\title{
The Lymph Node Ratio Is an Independent Prognostic Factor in Pancreatic Cancer Patients Who Receive Curative Resection Followed by Adjuvant Chemotherapy
}

\author{
TORU AOYAMA ${ }^{1,2^{*}}$, NAOTO YAMAMOTO $^{1,2^{*}}$, MARIKO KAMIYA ${ }^{1,2}$, MASAAKI MURAKAWA $^{1,2}$, \\ HIROSHI TAMAGAWA $^{1,2}$, SHO SAWAZAKI ${ }^{1,2}$, MASAKATSU NUMATA $^{1,2}$, MANABU SHIOZAWA $^{1}$, \\ SATOSHI KOBAYASHI ${ }^{3}$, MAKOTO UENO ${ }^{3}$, MANABU MORIMOTO $^{3}$, NORIO YUKAWA ${ }^{2}$, TAKASHI OSHIMA ${ }^{2}$, \\ TAKAKI YOSHIKAWA ${ }^{2}$, YASUSHI RINO ${ }^{2}$, MUNETAKA MASUDA ${ }^{2}$ and SOICHIRO MORINAGA ${ }^{1}$ \\ ${ }^{1}$ Department of Gastrointestinal Surgery, Kanagawa Cancer Center, Yokohama, Japan; \\ ${ }^{2}$ Department of Surgery, Yokohama City University, Yokohama, Japan; \\ ${ }^{3}$ Department of Gastroenterology, Hepatobiliary and Pancreatic Medical Oncology Division, \\ Kanagawa Cancer Center, Yokohama, Japan
}

\begin{abstract}
Background/Aim: The present study investigated the impact of the lymph node ratio (LNR) on survival and recurrence in patients with pancreatic cancer after curative surgery followed by adjuvant chemotherapy. Patients and Methods: This study included 189 patients who underwent curative surgery followed by adjuvant chemotherapy for pancreatic cancer between 2005 and 2014. The risk factors for overall survival (OS) and recurrence-free survival (RFS) were identified. Results: A lymph node ratio of 0.1 was considered to be the optimal cut-off point for classification based on the 3-year and 5-year survival rates. The OS rates at three and five years after surgery were $34.4 \%$ and $28.2 \%$ in the $L N R<0.1$ group, respectively, and $23.1 \%$ and $5.8 \%$ in the $L N R \geq 0.1$ group, which amounted to a statistically significant difference ( $p=0.003)$. The RFS rates at one and three years after surgery were $26.6 \%$ and $20.5 \%$ in the LNR $<0.1$ group, respectively, and $8.0 \%$ and $0 \%$ in the $L N R \geq 0.1$ group, which was a significant difference $(p=0.001)$. A multivariate analysis demonstrated that the LNR was a significant independent risk factor for both the OS and RFS. Conclusion: The LNR was a risk factor for overall survival
\end{abstract}

\footnotetext{
*These Authors equally contributed to this study.

Correspondence to: Soichiro Morinaga, Department of Gastrointestinal Surgery, Kanagawa Cancer Center, 2-3-2 Nakao, Asahi-ku, Yokohama 241-8515, Japan. Tel: +81 455202222, e-mail: morinagas@kcch.jp; and Toru Aoyama, Department of Gastrointestinal Surgery, Kanagawa Cancer Center, 2-3-2 Nakao, Asahi-ku, Yokohama 241-8515, Japan. Tel: +81 457872800, e-mail: aoyamat@yokohama-cu.ac.jp
}

Key Words: Pancreatic cancer, lymph node ratio, survival, recurrence. in patients who underwent curative surgery followed by adjuvant chemotherapy for pancreatic cancer. It is necessary to develop strategies to effectively utilize the lymph node metastasis status.

Pancreatic cancer, which has a 5-year survival rate of less than $5 \%$, is a major cause of cancer death worldwide $(1,2)$. Complete resection is essential for obtaining a cure in patients with pancreatic cancer. However, pancreatic cancer patients suffer recurrence, even after complete curative resection followed by adjuvant treatment $(3,4)$. It is, therefore, important to identify the prognostic factors for pancreatic cancer in order to select candidates for more aggressive treatment.

Various clinicopathological factors, including the tumor size, lymph node metastasis, resection margin status, and histological type, have been reported to be significant prognostic factors that can be used to predict survival in patients with pancreatic cancer (5-8). Lymph node metastasis is one of the most important factors for recurrence and metastasis in pancreatic cancer $(9,10)$. Previously, the Union for International Cancer Control (UICC) staging system simply provided the LN classification, according to the absence or presence of LN metastasis (11). At present, the new 8th edition of the UICC classification of TNM staging includes relevant changes for pancreatic cancer (12). However, they did not define the number of the harvest lymph nodes that should be evaluated in detail. To improve the survival of pancreatic cancer patients, it is necessary to develop strategies that utilize the lymph node metastasis status more effectively.

Recently, the lymph node ratio (LNR), which is defined as the ratio of the number of metastatic LNs (MLN) to the total number of LNs (TLN) examined, has been proposed to be a 
sensitive indicator of survival in patients with pancreatic cancer (13-16). However, these previous reports analyzed less than 100 cases and included patients who were treated with surgery alone. The outcomes of patients with pancreatic cancer have gradually been improved by effective adjuvant chemotherapies such as gemcitabine or S-1 $(17,18)$. Theoretically, effective adjuvant chemotherapy can improve patient survival by inhibiting micrometastasis. Thus, it is unclear whether the LNR has any clinical impact in pancreatic cancer patients who undergo radical surgery and effective adjuvant chemotherapy.

The present study investigated whether the overall survival (OS) and recurrence-free survival (RFS) of pancreatic cancer patients who underwent curative surgery followed by adjuvant chemotherapy were affected by the LNR.

\section{Patients and Methods}

Patients. The study subjects were selected from the medical records of consecutive patients who underwent surgical treatment for pancreatic cancer at the Kanagawa Cancer Center from 2005 to 2014. The inclusion criteria were as follows: 1) patients with a common pathological type of pancreatic cancer (according to UICC TNM 7th edition); 2) patients in whom curative resection was successful as the initial treatment for pancreatic cancer and who received gemcitabine or S-1 adjuvant chemotherapy; and 3) the absence of synchronous or metachronous malignancies. The resected specimens were examined histopathologically and were staged according to the UICC TNM 7th edition. Patients with other pancreatic and periampullary neoplasms, such as intraductal papillary mucinous neoplasms, cystadenocarcinoma and endocrine tumors, were excluded from the present study.

Surgical procedure. All of the operations were performed by four surgeons from the pancreatic unit. All pancreatic surgeries were performed in accordance with standardized procedures that have been described elsewhere (19-22). Briefly, in cases of pancreaticoduo-denectomy (PD), subtotal stomach-preserving pancreaticoduo-denectomy was performed as the standard procedure. The lymph node groups that were resected en bloc included the anterior pancreatic duodenal lymph nodes, the posterior pancreatic duodenal lymph nodes, the nodes in the lower hepatoduodenal ligament, and the nodes along the right lateral aspect of the superior mesenteric artery and vein. In cases of distal pancreatectomy (DP), lymph node dissection was performed in the region of the celiac trunk and the superior mesenteric artery and vein, as well as behind the pancreas along the left side of the renal vein and the left adrenal gland (23).

Adjuvant chemotherapy. Treatment with gemcitabine was initiated within eight weeks after surgery. The patients received a weekly dose of $1,000 \mathrm{mg} / \mathrm{m}^{2}$ for three weeks, followed by one week of rest. S-1 chemotherapy was started within 10 weeks after surgery (17). The patients received $40 \mathrm{mg}$ of S-1 per square meter of bodysurface area, twice a day for four weeks, followed by two weeks of rest as one course (six-week schedule) or two weeks followed by one week of rest as one course (three-week schedule) (18). All of the patients in the present study received either gemcitabine or S-1 treatment for six months.
Table I. Comparison of survival rates stratified by patient characteristics.

\begin{tabular}{|c|c|c|c|c|c|}
\hline Characteristics & $\begin{array}{c}\text { No. of } \\
\text { patients } \\
(\%)\end{array}$ & $\begin{array}{l}\text { 1-year } \\
\text { survival } \\
\text { rate }(\%)\end{array}$ & $\begin{array}{l}\text { 3-year } \\
\text { survival } \\
\text { rate }(\%)\end{array}$ & $\begin{array}{l}5 \text {-year } \\
\text { survival } \\
\text { rate }(\%)\end{array}$ & $p$-Value \\
\hline Age (years) & & & & & 0.202 \\
\hline$<70$ & $110(58.2)$ & 75.8 & 28.2 & 21.9 & \\
\hline$>70$ & $79(41.8)$ & 86.7 & 27.3 & 17.5 & \\
\hline Gender & & & & & 0.406 \\
\hline Male & 107 (56.6) & 79.7 & 32.7 & 22.0 & \\
\hline Female & $82(43.4)$ & 80.0 & 23.0 & 14.4 & \\
\hline Site of tumor & & & & & 0.169 \\
\hline Head & $129(68.3)$ & 82.5 & 24.8 & 15.0 & \\
\hline Body or tail & $60(31.7)$ & 84.7 & 40.8 & 26.4 & \\
\hline $\begin{array}{l}\text { Metastatic lymph } \\
\text { node ratio }\end{array}$ & & & & & 0.021 \\
\hline $0 \%$ to $5 \%$ & $63(33.3)$ & 83.7 & 30.6 & 21.8 & \\
\hline $5 \%$ to $<10 \%$ & $33(17.5)$ & 79.2 & 38.1 & 38.1 & \\
\hline $10 \%$ to $<15 \%$ & $25(13.2)$ & 78.6 & 16.4 & 0 & \\
\hline $15 \%-$ & $68(36.0)$ & 76.9 & 17.8 & 8.9 & \\
\hline Histological type & & & & & 0.532 \\
\hline Well-mod & $153(81.0)$ & 80.8 & 29.4 & 20.3 & \\
\hline Poor & $36(19.0)$ & 75.6 & 23.5 & 23.5 & \\
\hline UICC $\mathrm{T}$ status & & & & & 0.031 \\
\hline $\mathrm{T} 1$ or $\mathrm{T} 2$ & $10(5.3)$ & 100.0 & 80.0 & 40.0 & \\
\hline $\mathrm{T} 3$ & 179 (94.7) & 78.9 & 27.0 & 14.7 & \\
\hline $\begin{array}{l}\text { Lymph node } \\
\text { metastasis }\end{array}$ & & & & & 0.026 \\
\hline Negative & $44(23.3)$ & 89.3 & 35.7 & 28.6 & \\
\hline Positive & 145 (76.7) & 77.0 & 25.9 & 12.9 & \\
\hline $\begin{array}{l}\text { Lymphovascular } \\
\text { invasion }\end{array}$ & & & & & 0.003 \\
\hline Negative & $33(17.5)$ & 96.6 & 46.4 & 34.8 & \\
\hline Positive & $156(82.5)$ & 76.1 & 25.4 & 11.9 & \\
\hline
\end{tabular}

ASA-PS: ASA physical status; UICC: Union for International Cancer Control.

Follow-up. Patients were followed-up at outpatient clinics. Hematological tests and physical examinations were performed at least every three months for five years. In the patients who received adjuvant chemotherapy, hematological tests and physical examinations were performed at least every two weeks during adjuvant chemotherapy, and at least every three months for five years after the patient finished adjuvant chemotherapy. The CEA and CA19-9 tumor marker levels were checked at least every three months for five years. Patients underwent CT examination every three months during the first three years after surgery, and then every six months until five years after surgery.

Evaluations and statistical analyses. The lymph node ratio (LNR) was defined as the ratio of the number of metastatic lymph nodes relative to the total number of lymph nodes examined. The significance of the correlation between the LNR and clinicopathological parameters was determined using Fisher's exact test or the $\chi^{2}$ test. OS was defined as the period between surgery and death. RFS was defined as the period between surgery and recurrence or death, whichever came first. The data of the patients 
Table II. Uni and Multivariate Cox proportional hazards analysis of clinicopathological factors for overall survival.

\begin{tabular}{|c|c|c|c|c|c|c|c|}
\hline \multirow[t]{2}{*}{ Factors } & \multirow[t]{2}{*}{ No } & \multicolumn{3}{|c|}{ Univariate analysis } & \multicolumn{3}{|c|}{ Multivariate analysis } \\
\hline & & OR & $95 \% \mathrm{CI}$ & $p$-Value & OR & $95 \% \mathrm{CI}$ & $p$-Value \\
\hline Age (years) & & & & 0.203 & & & \\
\hline$<70$ & 110 & 1.000 & & & & & \\
\hline$\geq 70$ & 79 & 1.320 & $0.860-2.026$ & & & & \\
\hline Gender & & & & 0.406 & & & \\
\hline Female & 82 & 1.000 & & & & & \\
\hline Male & 107 & 1.186 & $0.793-1.774$ & & & & \\
\hline Metastatic lymph node ratio & & & & 0.004 & & & 0.009 \\
\hline$<10 \%$ & 96 & 1.000 & & & 1.000 & & \\
\hline$\geq 10 \%$ & 93 & 1.822 & $1.217-2.728$ & & 1.748 & $1.147-2.665$ & \\
\hline Site of tumor & & & & 0.171 & & & 0.074 \\
\hline Body or Tail & 60 & 1.000 & & & 1.000 & & \\
\hline Head & 129 & 1.361 & $0.875-2.116$ & & 1.507 & $0.961-2.364$ & \\
\hline Histological type & & & & 0.532 & & & \\
\hline Well-mod & 153 & 1.000 & & & & & \\
\hline Poor & 36 & 1.183 & $0.699-2.002$ & & & & \\
\hline UICC T status & & & & 0.048 & & & \\
\hline $\mathrm{T} 1-\mathrm{T} 2$ & 10 & 1.000 & & & & & \\
\hline $\mathrm{T} 3$ & 179 & 4.128 & $1.015-16.782$ & & & & \\
\hline Lymph node metastases & & & & 0.028 & & & \\
\hline Negative & 44 & 1.000 & & & & & \\
\hline Positive & 145 & 1.764 & $1.065-2.922$ & & & & \\
\hline Lymphovascular invasion & & & & 0.005 & & & 0.002 \\
\hline Negative & 33 & 1.000 & & & 1.000 & & \\
\hline Positive & 156 & 2.326 & $1.294-4.181$ & & 2.002 & $1.100-3.646$ & \\
\hline
\end{tabular}

UICC: Union for International Cancer Control.

who did not experience an event were censored on the date of the final observation. OS and RFS were evaluated by univariate and multivariate analyses. OS and RFS curves were determined using the Kaplan-Meier method, and were compared by a log-rank test. A Cox proportional hazards model was used to perform the univariate and multivariate survival analyses. $p$-Values of $<0.05$ were considered to indicate statistical significance. The survival data were obtained from hospital records or from the city registry system. The SPSS software program (v11.0 J Win, SPSS, Chicago, IL, USA) was used for all of the statistical analyses. This study was approved by the IRB of the Kanagawa Cancer Center.

\section{Results}

Patients. A total of 189 patients were evaluated (median age, 67 years; range $=30-81$ years; male, $n=107$; female, $n=82$ ) in the present study. The median follow-up period was 60.5 months (range $=7.8-137$ months). Forty-six patients received distal pancreatic surgery, 129 patients received pancreaticoduodenectomy and 14 underwent total pancreatic resection. The median operative time was $483 \mathrm{~min}$ (range $=140-1195 \mathrm{~min}$ ). The median blood loss was $1020 \mathrm{ml}$ (range $=30-10175 \mathrm{ml}$ ). The median number of harvested lymph nodes was 26 (range $=1-92$ lymph nodes).
Survival analysis. A log-rank test was performed to investigate the factors associated with overall survival; significant differences were observed in the lymph node ratio, $\mathrm{T}$ factor, $\mathrm{N}$ factor, and lymphovascular invasion (Table I). A lymph node ratio of 0.1 was considered to be the optimal cutoff point for classification based on the 3-year and 5-year survival rates.

The prognostic significance of each clinicopathological factor was analyzed (Table II). The univariate analyses of the factors associated with OS demonstrated that the LNR was a significant prognostic factor. Thus, the LNR was included in the final multivariate analysis model. The OS rates at three and five years after surgery were $34.4 \%$ and $28.2 \%$ in the LNR $<0.1$ group, respectively, and $23.1 \%$ and $5.8 \%$ in the LNR $\geq 0.1$ group, which amounted to a statistically significant difference $(p=0.003)$. The OS curves are shown in Figure 1.

The univariate analyses of the factors associated with RFS demonstrated that the LNR was a significant prognostic factor. Thus, the LNR was included in the final multivariate analysis model (Table III). The RFS rates at one and three years after surgery were $26.6 \%$ and $20.5 \%$ in the $\mathrm{LNR}<0.1$ group, respectively, and $8.0 \%$ and $0 \%$ in the $\mathrm{LNR} \geq 0.1$ group, 
Table III. Uni- and Multivariate Cox proportional hazards analysis of clinicopathological factors for recurrence-free survival.

\begin{tabular}{|c|c|c|c|c|c|c|c|}
\hline \multirow[t]{2}{*}{ Factors } & \multirow[t]{2}{*}{ Number } & \multicolumn{3}{|c|}{ Univariate analysis } & \multicolumn{3}{|c|}{ Multivariate analysis } \\
\hline & & OR & $95 \% \mathrm{CI}$ & $p$-Value & OR & $95 \% \mathrm{CI}$ & $p$-Value \\
\hline Age (years) & & & & 0.079 & & & 0.052 \\
\hline$<70$ & 110 & 1.000 & & & 1.000 & & \\
\hline$\geq 70$ & 79 & 1.396 & $0.962-2.027$ & & 1.450 & $0.997-2.110$ & \\
\hline Gender & & & & 0.400 & & & \\
\hline Female & 82 & 1.000 & & & & & \\
\hline Male & 107 & 1.167 & $0.815-1.671$ & & & & \\
\hline Metastatic lymph node ratio & & & & 0.002 & & & 0.027 \\
\hline$<10 \%$ & 96 & 1.000 & & & 1.000 & & \\
\hline$\geq 10 \%$ & 93 & 1.797 & $1.244-2.597$ & & 1.537 & $1.049-2.251$ & \\
\hline Site of tumor & & & & 0.225 & & & \\
\hline Body or Tail & 60 & 1.000 & & & & & \\
\hline Head & 129 & 1.272 & $0.863-1.874$ & & & & \\
\hline Histological type & & & & 0.406 & & & \\
\hline Well-mod & 153 & 1.000 & & & & & \\
\hline Poor & 36 & 1.213 & $0.769-1.916$ & & & & \\
\hline UICC $\mathrm{T}$ status & & & & 0.019 & & & \\
\hline $\mathrm{T} 1-\mathrm{T} 2$ & 10 & 1.000 & & & & & \\
\hline $\mathrm{T} 3$ & 179 & 3.980 & $1.261-12.567$ & & & & \\
\hline Lymph node metastases & & & & 0.035 & & & \\
\hline Negative & 44 & 1.000 & & & & & \\
\hline Positive & 145 & 1.621 & $1.035-2.538$ & & & & \\
\hline Lymphovascular invasion & & & & 0.002 & & & 0.007 \\
\hline Negative & 33 & 1.000 & & & 1.000 & & \\
\hline Positive & 156 & 2.212 & $1.333-3.668$ & & 2.050 & $1.214-3.461$ & \\
\hline
\end{tabular}

ASA-PS: ASA physical status; UICC: Union for International Cancer Control.

which was a significant difference $(p=0.001)$. The RFS curves are shown in Figure 2. When the sites of first relapse were compared, the incidence of lymph node metastasis in the $L N R \geq 0.1$ group was significantly higher than that in the $\mathrm{LNR}<0.1$ group.

\section{Discussion}

The present study examined whether the LNR was associated with poorer overall survival and recurrence-free survival in pancreatic cancer patients who underwent curative surgery followed by adjuvant chemotherapy. Our findings clearly indicated that the LNR was an independent risk factor for both OS and RFS. Moreover, the results of the present study suggested that the LNR was closely associated with lymph node recurrence. Thus, the LNR had a clinical impact in pancreatic cancer patients who underwent radical surgery and effective adjuvant chemotherapy.

The clinical impact of the LNR in pancreatic cancer patients has been reported in previous studies $(14,24)$. In the present study, the hazard ratio for OS was $1.748(95 \%$ confidence interval, 1.147 to 2.665 ) and that for RFS was 1.537 (95\% confidence interval, 1.049 to 2.251 ). A similar hazard ratio and $95 \%$ confidence interval were observed in previous studies $(14,24)$. Tol et al. examined 760 pancreatic cancer patients and found that the lymph node ratio was independently associated with worse overall survival (hazard ratio of $1.75,95 \%$ confidence interval, 1.13 to 2.70$)$ (24). In addition, Murakami et al. examined 119 pancreatic cancer patients and found that the metastatic lymph node ratio was independently associated with worse overall survival (hazard ratio of $2.685,95 \%$ confidence interval, 1.253 to 5.756 ) (14). Similar hazard ratios were also reported in other studies. Thus, the LNR had some clinical impact on the survival of patients with pancreatic cancer.

An important limitation that potentially affects the available data regarding the LNR in all studies - including the current study - is the lack of consensus regarding the most appropriate cut-off point for the LNR. In previous studies, the LNRs ranged from 0.1 to 0.4 . For example, Zhan et al. evaluated the prognostic impact of the LNR in 83 patients with resected pancreatic cancer. They used a cut-off LNR of 0.2 and demonstrated the hazard ratio (25). Tol et al. evaluated the prognostic impact of the LNR in 760 patients with resected pancreatic cancer (24). They set a cut-off LNR of 0.18 and demonstrated the hazard ratio. In our study, we used a cut-off 


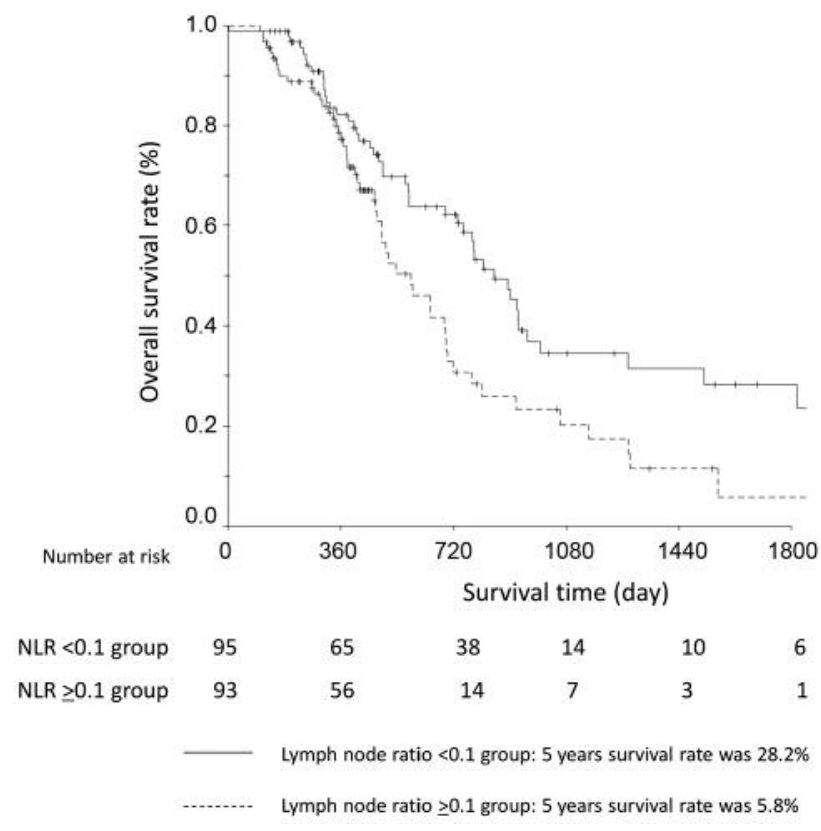

Figure 1. A comparison of the overall survival in the $L N R \geq 0.1$ and $L N R<0.1$ groups.

LNR of 0.1 based on the three- and five-year survival. There are some differences between the previous studies and the present study. First, the sample size was different. The previous studies analyzed relatively small study populations, while the present study analyzed 186 cases. Second, the previous reports only analyzed patients who were treated with surgery alone. The outcomes of patients with pancreatic cancer have gradually improved with effective adjuvant chemotherapies such as gemcitabine or S-1. Theoretically, effective adjuvant chemotherapy can improve patient survival by inhibiting micrometastasis. Actually, the previous study demonstrated that perioperative adjuvant treatment was associated with a reduced LNR in patients with potentially resectable pancreatic cancer (26). Third, the median number of harvested lymph nodes in the present study differed from that in previous studies. The LNR was affected by both the harvested lymph nodes and the number of metastatic lymph nodes. In the present study, the median number of harvested lymph nodes was 26 and the cut-off LNR was 0.1 . Similar to our study, Robinson et al. reported that the median number of harvested lymph nodes was 19 and that the cut-off LNR was 0.15 (13). In contrast, Zhan et al. reported that the mean number of harvested lymph nodes was 8.2 and that the cut-off LNR was 0.2 (25). Moreover, Tol et al. reported that the median number of harvested lymph nodes was 8 and that the cut-off LNR was 0.2 (24). On the other hand, the median

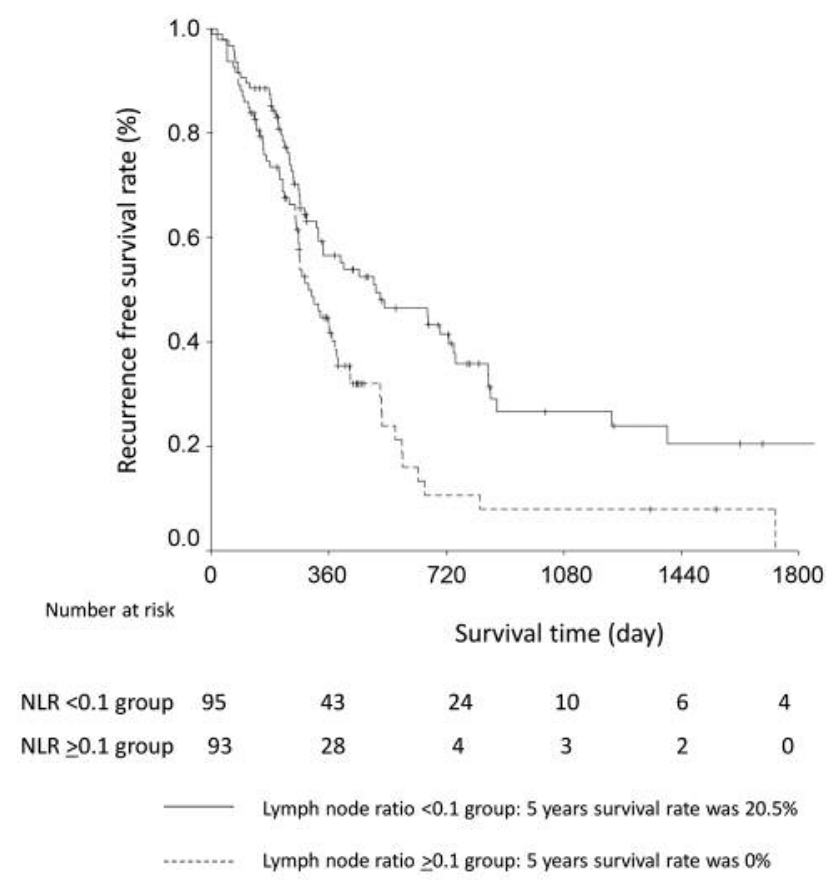

Figure 2. A comparison of the recurrence-free survival in the $L N R \geq 0.1$ and $L N R<0.1$ groups.

number of metastatic lymph nodes in the present study was similar to that in previous studies. These differences might have affected the cut-off LNR values.

Special attention is required when interpreting the results of the present study due to several potential limitations. First, the present study was a retrospective analysis that was performed in a single institution. Second, there was a selection bias in the patients in this series. Surgeons often avoid performing pancreatomy in some patients, because the procedure is associated with high rates of morbidity and mortality (40-60\% and $1-1.5 \%$, respectively). Thus, the fact that some patients in this study received pancreatectomy could in and of itself be considered a potential bias. In addition, our hospital is a specialized cancer center. Considering these limitations, the results must be confirmed in another cohort or in a prospective multicenter-study.

In conclusion, the OS and RFS of pancreatic cancer patients who underwent curative resection followed by adjuvant chemotherapy differed significantly based on the LNR. It is necessary to develop a strategy that effectively utilizes the lymph node metastasis status.

\section{Conflicts of Interest}

The Authors declare no conflicts of interest in association with the present study. 


\section{Acknowledgements}

This work was supported, in part, by the Kanagawa Prefectural Hospitals Cancer Fund and the Takeda Science Foundation.

\section{References}

1 Torre LA, Bray F, Siegel RL, Ferlay J, Lortet-Tieulent J and Jemal A: Global cancer statistics, 2012. CA Cancer J Clin 65: 87-108, 2015.

2 Jemal A, Siegel R, Xu J and Ward E: Cancer statistics, 2010. CA Cancer J Clin 60: 277-300, 2010.

3 Kamisawa T, Wood LD, Itoi T and Takaori K: Pancreatic cancer. Lancet 388: 73-85, 2016.

4 Vincent A, Herman J, Schulick R, Hruban RH and Goggins ML: Pancreatic cancer. Lancet 378: 607-620, 2011.

5 Winter JM, Cameron JL, Campbell KA, Arnold MA, Chang DC, Coleman J, Hodgin MB, Sauter PK, Hruban RH, Riall TS, Schulick RD, Choti MA, Lillemoe KD and Yeo CJ: 1423 pancreaticoduodenectomies for pancreatic cancer: A singleinstitution experience. J Gastrointest Surg 10: 1199-1210, 2006.

6 Sohn TA, Yeo CJ, Cameron JL, Koniaris L, Kaushal S, Abrams RA, Sauter PK, Coleman J, Hruban RH and Lillemoe KD: Resected adenocarcinoma of the pancreas-616 patients: results, outcomes, and prognostic indicators. J Gastrointest Surg 4: 567-579, 2000.

7 Moon HJ, An JY, Heo JS, Choi SH, Joh JW and Kim YI: Predicting survival after surgical resection for pancreatic ductal adenocarcinoma. Pancreas 32: 37-43, 2006.

8 Kuhlmann KF, de Castro SM, Wesseling JG, ten Kate FJ, Offerhaus GJ, Busch OR, van Gulik TM, Obertop H and Gouma DJ: Surgical treatment of pancreatic adenocarcinoma; actual survival and prognostic factors in 343 patients. Eur J Cancer 40 : 549-58, 2004.

9 Lim JE, Chien MW and Earle CC: Prognostic factors following curative resection for pancreatic adenocarcinoma: a populationbased, linked database analysis of 396 patients. Ann Surg 237: 74-85, 2003.

10 Kuhlmann KF, de Castro SM, Wesseling JG, ten Kate FJ, Offerhaus GJ, Busch OR, van Gulik TM, Obertop H and Gouma DJ: Surgical treatment of pancreatic adenocarcinoma; actual survival and prognostic factors in 343 patients. Eur J Cancer 40 : 549-58, 2004.

11 Sobin LH, Gospodarowicz MK and Wittekind Ch: TNM classification of malignant tumours. 7th edition. Chichester, West Sussex, UK; Hoboken, NJ: Wiley-Blackwell, 2010

12 Brierley J, Gospodarowicz MK and Wittekind Ch: TNM classification of malignant tumours. 8th edition. Chichester, West Sussex, UK; Hoboken, NJ: John Wiley \& Sons, Inc., 2017.

13 Robinson SM, Rahman A, Haugk B, French JJ, Manas DM, Jaques BC, Charnley RM and White SA: Metastatic lymph node ratio as an important prognostic factor in pancreatic ductal adenocarcinoma. Eur J Surg Oncol 38: 333-339, 2012.

14 Murakami Y, Uemura K, Sudo T, Hayashidani Y, Hashimoto Y, Nakashima A, Yuasa Y, Kondo N, Ohge H and Sueda T: Number of metastatic lymph nodes, but not lymph node ratio, is an independent prognostic factor after resection of pancreatic carcinoma. J Am Coll Surg 211: 196-204, 2010.

15. Yamamoto Y, Ikoma H, Morimura R, Konishi H, Murayama Y, Komatsu S, Shiozaki A, Kuriu Y, Kubota T, Nakanishi M, Ichikawa D, Fujiwara H, Okamoto K, Sakakura C, Ochiai T and
Otsuji E: The clinical impact of the lymph node ratio as a prognostic factor after resection of pancreatic cancer. Anticancer Res 34: 2389-2394, 2014.

16 Liu ZQ, Xiao ZW, Luo GP, Liu L, Liu C, Xu J, Long J, Ni QX and Yu XJ: Effect of the number of positive lymph nodes and lymph node ratio on prognosis of patients after resection of pancreatic adenocarcinoma. Hepatobiliary Pancreat Dis Int 13: 634-641, 2014.

17 Uesaka K, Boku N, Fukutomi A, Okamura Y, Konishi M, Matsumoto I, Kaneoka Y, Shimizu Y, Nakamori S, Sakamoto H, Morinaga S, Kainuma O, Imai K, Sata N, Hishinuma S, Ojima H, Yamaguchi R, Hirano S, Sudo T and Ohashi Y: Adjuvant chemotherapy of S-1 versus gemcitabine for resected pancreatic cancer: a phase 3, open-label, randomised, non-inferiority trial (JASPAC 01). Lancet 388: 248-257, 2016.

18 Oettle H, Post S, Neuhaus P, Gellert K, Langrehr J, Ridwelski K, Schramm H, Fahlke J, Zuelke C, Burkart C, Gutberlet K, Kettner E, Schmalenberg H, Weigang-Koehler K, Bechstein WO, Niedergethmann M, Schmidt-Wolf I, Roll L, Doerken B and Riess H: Adjuvant chemotherapy with gemcitabine vs. observation in patients undergoing curative-intent resection of pancreatic cancer: a randomized controlled trial. JAMA 297: 267-277, 2007.

19 Büchler MW, Friess H, Wagner M, Kulli C, Wagener V and Z'Graggen K: Pancreatic fistula after pancreatic head resection. Br J Surg 87: 883-889, 2000.

20 Wagner M, Z'graggen K, Vagianos CE, Redaelli CA, Holzinger F, Sadowski C, Kulli C, Zimmermann H, Baer HU and Büchler MW: Pylorus-preserving total pancreatectomy. Early and late results. Dig Surg 18: 188-195, 2001.

21 Andrén-Sandberg A, Wagner M, Tihanyi T, Löfgren P and Friess $\mathrm{H}$ : Technical aspects of left-sided pancreatic surgery for cancer. Dig Surg 16: 305-312, 1999.

22 Seiler CA, Wagner M, Sadowski C, Kulli C and Büchler MW: Randomized prospective trial of pylorus-preserving vs. Classic duodenopancreatectomy (Whipple procedure): initial clinical results. J Gastrointest Surg 4: 443-452, 2000.

23 Murakawa M, Aoyama T, Asari M, Katayama Y, Yamaoku K, Kanazawa A, Higuchi A, Shiozawa M, Kobayashi S, Ueno M, Morimoto M, Yamamoto N, Yoshikawa T, Rino Y, Masuda M and Morinaga S: The short- and long-term outcomes of radical antegrade modular pancreatosplenectomy for adenocarcinoma of the body and tail of the pancreas. BMC Surg 15: 120, 2015.

24 Tol JA, Brosens LA, van Dieren S, van Gulik TM, Busch OR, Besselink MG and Gouma DJ: Impact of lymph node ratio on survival in patients with pancreatic and periampullary cancer. $\mathrm{Br}$ J Surg 102: 237-245, 2015.

25. Zhan HX, Xu JW, Wang L, Zhang GY and Hu SY: Lymph node ratio is an independent prognostic factor for patients after resection of pancreatic cancer. World J Surg Oncol 13: 105, 2015.

26 Roland CL, Yang AD, Katz MH, Chatterjee D, Wang H, Lin H, Vauthey JN, Pisters PW, Varadhachary GR, Wolff RA, Crane CH, Lee JE and Fleming JB: Neoadjuvant therapy is associated with a reduced lymph node ratio in patients with potentially resectable pancreatic cancer. Ann Surg Oncol 22: 1168-1175, 2015.

Received June 6, 2018

Revised June 16, 2018

Accepted June 19, 2018 